\title{
ENTREVISTA
}

\section{As Ruínas Emergentes da Modernidade e a Pós-Modernidade ENTREVISTA COM BOAVENTURA DE SOUZA SANTOS}

\author{
Por Dilmar Santos de Miranda, Juan Félix \\ Marteau, Marcos Alberto Costa, Maria Eduarda \\ Rocha e Rodrigo Vinicius dos Santos Motta*
}

Boaventura de Sousa Santos é sociólogo e Doutor em Sociologia do Direito pela Universidade de Yale, EUA. É Professor Catedrático da Faculdade de Economia da Universidade de Coimbra e Diretor do Centro de Documentação 25 de Abril daquela universidade. Ao longo dos últimos vinte e cinco anos, Sousa Santos escreveu extensivamente sobre Sociologia do Direito e do Estado, tanto nas sociedades capitalistas centrais, como nas sociedades periféricas. Os resultados das pesquisas empíricas que realizou nas favelas do Rio de Janeiro e de Recife, em Portugal e em Cabo Verde suscitaram-lhe reflexões teóricas publicadas nas mais significativas revistas cien-

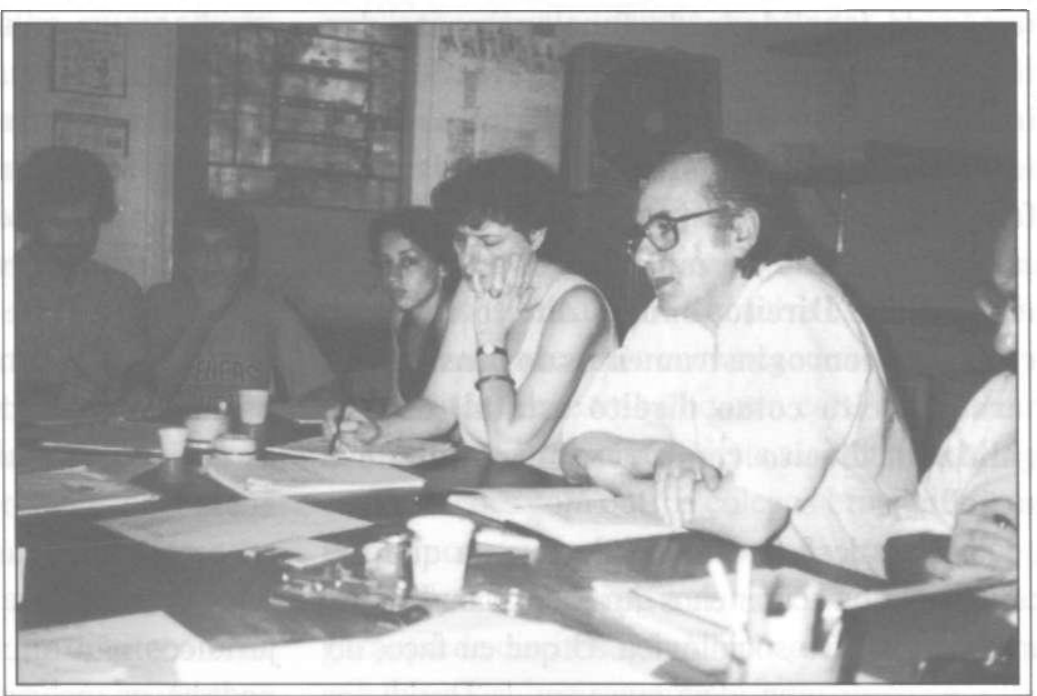

Professor Boaventura confere palestra no Núcleo de Estudos da Violência (USP). tíficas internacionais. Sobre o Brasil, onde desenvolveu pesquisas de campo na favela do Jacarezinho (RJ), escreveu um de seus principais livros: The law of the opressed, publicado pela Universidade de Yale, em 1974, pela Law and Society Review em 1977 e, no Brasil, pela Universidade de Brasília, em 1989. Seus mais recentes livros são Pela Mão de Alice (Editora Afrontamento, Porto, 1994 e Cortez Editora, São Paulo, 1995) e Toward a New Common Sense: Law, Science and Politics in the Paradigmatic Transation (Routledge, Nova Iorque, 1995). Tem sido Professor Visitante em várias universidades, entre as quais se destacam: a Universidade de Madison (Wisconsin) e a London School of Economics and Political Science (Londres). No segundo semestre de 1995, Sousa Santos esteve em São Paulo, como professor convidado do Programa de Pós-Graduação em Sociologia da Faculdade de Filosofia, Letras e Ciências Humanas da Universidade de São Paulo (FFLCH/USP), onde ministrou a disciplina "As Ruínas Emergentes: das modernidades à transição paradigmática". $\mathrm{Na}$ ocasião, concedeu a entrevista que segue para a Revista Plural.

\footnotetext{
`Dilmar Santos de Miranda, Juan Félix Marteau, MarcosAlberto Costa, Maria Eduarda Rocha e Rodrigo Vinicius dos Santos Motta são alunos do Programa de Pós-Graduação em Sociologia da FFLCH/USP.

Edição: Marina Albuquerque de Macedo Soares, doutoranda do Departamento de Sociologia (USP).
} 
P. O direito, ou melhor, as práticas jurídicas, ocupam um lugar privilegiado em seus variados objetos de reflexão. Nos anos setenta, o senhor dedicou-se ao estudo do direito não oficial nas favelas do Rio de Janeiro. Nos anos oitenta, interessou-se pelos problemas da legalização de terras que enfrentavam os favelados do Recife. Em Portugal, e mais tarde em Cabo Verde, a questão da legalidade do funcionamento dos tribunais populares foram objeto de uma minuciosa análise empírica. Poderiamos dizer que, se existe um fio teórico que articula esses diferentes trabalhos, este seria a preocupação com a construção de um novo objeto para a Sociologia do Direito, onde o direito deixa de ser pensado com os instrumentos do pensamento liberal, direito como direito estatal, direito legalidade, direito como responsabilidade e sanção?

R. De fato, desde a década de setenta que me interesso pelos fenômenos jurídicos, analisados numa perspectiva sociológica. $\mathrm{O}$ que eu faço, no fundo, é seguir uma idéia que vem de Durkheim que, como sabem, sempre considerou o direito um ótimo indicador - ou um bom indicador - de formas de sociabilidade. Quando ele distingue diferentes formas de solidariedade, relaciona-as com dominâncias diferentes dos fenômenos jurídicos. Portanto, eu continuo a pensar que o direito é, ainda hoje, um bom indicador sobre as formas de sociabilidade vigentes nas nossas socicdades. No entanto, para que assim seja - e esse é o meu intcresse no dircito enquanto objeto sociológico e no âmbito da construção de uma teoria sociológica mais ampla, na qual, aliás, são muito importantes as preocupações epistemológicas - é preciso colocar o direito fora do nicho liberal e fora daquela concepção, que é uma concepção extremamente recente da modernidade capitalista. Essa concepção consiste, basicamentc, $\mathrm{cm}$ considerar-sc que em cada sociedade há apenas um direito oficial - que é o direito do Estado - do qual o Estado tem monopólio, que ć administrado por profissões jurídicas, as quais têm a mesma organização burocrática em quase todos os países. Os cidadãos em geral não têm o poder de entrar nesse cspaço $\mathrm{c}$ nesse discurso jurídico enquanto tal, apenas entram seus interesses e eles cstão a cargo de profissionais: advogados, promotores, ctc. Em termos sociológicios, este campo jurídico oficial coexiste na sociedasde com outros campos jurídicos não oficiais e estes tendem a ser muito importantes para as classcs populares, as quais de resto não têm accsso ao direito oficial scnão como réus $\mathrm{cm}$ processos criminais. A fábrica, os bairros marginais, a economia informal configuram campos jurídicos não oficiais. Nestes campos jurídicos, pode haver, inclusive, polícias, pode haver sanções, há, certamente, normas, podc haver tribunais. $\mathrm{Ou}$ scja, no direito não ofiicial encontramos uma estrutura diferente da do direito do Estado, mas as características culturais das duas formas jurídicas podem ser convergentes. Eu costumo distingüir esses três grandes elementos culturais do direito: a retórica, a violência e a burocracia. Portanto, no fundo, a diferença entre os campos jurídicos decorre das difercntes combinações entre estes elementos. $\mathrm{O}$ mcu intcresse pclo direito não oficial dccorre, por um lado, de ser um direito, muitas vezes menos democrático que o direito 
oficial que é o único disponível para as classes populares e, por outro lado, de ser um direito mais livre para o estudo sociológico, uma vez que os juristas nunca lhe deram qualquer atenção.

P. Atualmente, sob sua direção, está se realizando uma exaustiva pesquisa sobre o poder judiciário em Portugal. $O$ senhor poderia nos dizer de que se trata esse trabalho, quais são as suas finalidades, como ele se insere no conjunto dos seus trabalhos sobre o direito e, principalmente, no desenvolvimento do pensamento pós-moderno sobre o direito? Como esse trabalho se articula com esse seu interesse pelo direito não oficial?

R. É evidente que não faz sentido, nas nossas sociedades contemporâneas, estudar apenas o jireito não oficial, o direito informal, os direitos saralelos. Eles são muito importantes porque a naioria da população resolve seus litígios sem - zcorrer aos tribunais oficiais e ao direito oficial e - evidente que o que fica fora do direito oficial -̇o é necessariamente "uma selva" e, sim, formas iternativas de se resolver os litígios. Mas é evisnte também que o direito oficial tem uma imporincia central: ele é o grande articulador, a grande -zguagem através da qual o Estado fala para a sciedade civil. O Estado fala para a socie-dade : sil, dirige-se à sociedade civil através de normas, I direitos, de regulamentos, de constituições e, sortanto, é muito importante conhecer os operado$\therefore$ os articuladores e as várias instituições desse -aito, especialmente os tribunais, que desempe-am um papel crucial nesse processo. Estes $r$ :manecem sempre na interface entre o Estado e a sociedade civil, na medida em que, sempre que há um litígio, é nos tribunais que eles são resolvidos, pelo menos quando os interessados recorrem ao direito jurídico oficial. E, portanto, se há ou não a garantia de direitos numa sociedade, isso avalia-se bem analisando-se sociologicamente como é que funcionam os tribunais. Foi dai que, a partir de meados da década de 80 , eu cheguei à conclusão de que, depois de estudar todas essas formas jurídicas paralelas, era preciso estudar o centro do sistema. E, para ir ao centro do sistema, talvez a melhor alternativa fosse estudar o judiciário. É uma análise do judiciário, na perspectiva de uma sociologia política e jurídica, na medida em que os tribunais são concebidos como órgãos de soberania que estão encarregados das garantias dos direitos. Esse trabalho está concluído, aliás o livro sai proximamente. ${ }^{1}$ Neste momento, estou em conversações com outros colegas brasileiros para lançarmos um projeto comparado entre Portugal e Brasil, entre Europa e América Latina, sobre a garantia de direitos no judiciário e a pergunta que nós fazemos, basicamente, é esta: quem é que usa os tribunais, para que e com que resultados? Uma pergunta sociológica, a qual, naturalmente, com nossos instrumentos sociológicos, estamos procurando responder.

\section{P. O senhor se define como um pós-moderno de oposição. $O$ senhor poderia dizer quais são as principais influências intelectuais na sua}

\footnotetext{
Santos, Boaventura de Sousa et al., 1996. Os tribunais nas sociedades contemporâneas: o caso português. Porto, Editora Afrontamento .
} 
trajetória acadêmica que levaram a essa definição? O senhor poderia explicitar as indefinições, continuidades, descontinuidades e rupturas que, por ventura, poderiam ser identificadas em sua trajetória?

R. Esta pergunta está formulada em "termos muito modernos". Ou seja, qualquer posição aí definida como intelectual, naturalmente se define apenas a partir de influências intelectuais... e isso é um pouco problemático. Algumas das minhas influências intelectuais são, por exemplo, o Sr. Jair, presidente da Associação de Moradores da Favela onde eu estive, no Rio de Janeiro; o Avregny, que treinava na favela as pessoas para irem ao INPS simular que eram loucas para obter certificados de invalidez. O Álvaro, que tratava da sala de ordenha de uma cooperativa que ajudei a fundar em Portugal, depois de 1974; o Sr. Abreu, que foi diretor dessa cooperativa durante muitos anos, com quem tive muitas conversas e bebi muito vinho na adega, depois das nossas longuissimas reuniões no inverno, quando ficávamos a conversar. Essas são verdadeiras influências formadoras, na medida em que a gente se habitua a ver que só por uma ilusão de ótica do nosso pensamento moderno é que a gente transforme o nosso conhecimento profissional num conhecimento separado dessas experiências. De fato, em todos nós, essas experiências, esses contatos com outras pessoas que têm uma grande sabedoria, que têm conhecimentos alternativos, que têm um senso comum de outro tipo, em certas épocas de nossas vidas, são muito importantes na formação do nosso pensamento. Agora, obviamente que isso não é tudo. Não é com elas que eu poderia fazer teoria sociológica. Essas pessoas foram importantes porque eram de um meio diferente do meu, de um contexto social diferente. $\mathbf{O}$ fato de eu ter decidido fazer as minhas primeiras pesquisas sociológicas através da observação participante, ou seja, vivendo na favela, alugando um barraco, partilhando a vida dos favelados, saindo na escola de samba do Jacarezinho, namorando na favela - o que, aliás, era uma transgressão metodológica! - tudo isso teve uma importância grande na minha formação, possibilitando-me conhecer diferentes contextos sociais. Para além disso, naturalmente, há outras influências também não diretamente intelectuais, que têm a ver com as trajetórias de vida de cada um. Eu estudei filosofia durante dois anos em Berlim, de 1963 a 1965 . Estudei na Universidade Livre de Berlim e lá cheguei pouco tempo depois de ter sido levantado o "Muro de Berlim". Acontece que a minha namorada era de Berlim Leste, o que significava que eu tinha de atravessar quase todos os dias o "Muro de Berlim". Essa experiência foi muito importante para mim e talvez ela explique, por exemplo, por que razão o meu pensamento crítico nunca teve uma opção política comunista. Eu tive um contato muito cedo, muito concreto, com a versão - nessa altura dominante - do que era o comunismo stalinista. Mas, naturalmente, essa época foi muito importante para mim, porque foi aí que eu entrei em contato com os primeiros dirigentes do movimento estudantil europeu. O Rudi Dutschke, que foi um grande líder estudantil na Alemanha, foi meu contemporâneo na universidade em Berlim. Era ai que se estava a gerar todo um movimento - através da Associação dos Estudantes Socialistas, o SDS, que 
mais tarde liderou o movimento estudantil na Alemanha - e depois um pouco também pelo resto da Europa. Esse cadinho de influências me foi muito importante.

Em 1969, eu fui para os Estados Unidos e fiquei lá até 1973. A situação em Portugal era insustentável para uma pessoa como eu, que queria fazer a viragem do direito e da filosofia para a sociologia. Era o final do regime ditatorial, tivemos várias crises estudantis em Portugal - em 62 e 69 - e, desta maneira, fui estudar nos Estados Unidos, em Yale, e lá cheguei em 1969, no auge do movimento estudantil. De certa maneira, nos Estados Unidos, o maio de 68 era, em 69 e 70, a grande manifestação estudantil, sobretudo contra a guerra no Vietnã. Portanto, grande parte da minha formação, inclusivemente "mais marxista", data desse período. Foi nitidamente uma tentativa de procurar uma teoria da oposição. Portanto, eu aprendi o marxismo não na Alemanha Oriental, mas em Yale, nos Estados Unidos, no centro do capitalismo mundial. A minha universidade era uma das melhores dos EUA e ainda hoje o é. Era lá que, naquela época se formavam - e ainda se formam - os grandes líderes para a vida econômica e política do país. Eu fiquei lá até 1973 .

P. Nos Estados Unidos, o senhor deve ter conhecido os grandes intelectuais do momento.

R. Sim, Marcuse estava do outro lado, na Califórnia, e era um homem muito importante. $\mathrm{O}$ Charles Reich, que escreveu Greening of America $^{2}$ era

2 Reich, Charles A, 1970, Renascer da América, Rio de Janeiro, Editora Record. meu professor. Foi um período de grandes transformações. Foi aí que eu conheci os Black Panters, foi aí que eu tive contato com todo o movimento de contestação e foi aí que nós começamos a criar grupos de estudo, por exemplo, para estudar marxismo na Universidade, grupos de estudo com colegas de pais tão diferentes como Etiópia, Israel e Chile. E, para além disso, formos freqüentando os cursos que então começaram a ser oferecidos. Até esse período, foram essas as grandes experiências que influenciaram na formação de minhas idéias. Chegando, agora, aos intelectuais que são os tais que são "muito importantes" na vossa pergunta, foram muitos e, naturalmente, há uma grande amálgama de influências. Eu diria que a mais marcante, espero vos surpreender, é Hegel, não o Hegel da Fenomenologia do Espírito, mas o Hegel de Da Ciência e da Lógica, que estudei longamente para tentar compreender as antinomias do pensamento ocidental e poder-lhes-ia dizer que foi estudando aquilo, que eu considero ser a melhor formulação do mito da filosofia ocidental, que eu comecei a dar-me conta dos limites desse pensamento. Foi aí que eu comecei a me interessar muito seriamente por pensamentos e pensadores que extravasassem essas fronteiras e, naturalmente, Nietzsche foi uma grande inspiração que veio muito cedo para mim. Muito antes de Foucault, Nietzsche, porque foi um dos homens que melhor desmontou a dialética hegeliana. Ele e Kierkegaard foram de grande influência nesse período. Eu lia praticamente tudo - naquela altura, eu podia lê-los no original, pois era mais fluente em alemão do que em inglês - e ler Hegel levou-me a outras influências do pensa- 
mento não ocidental. É aí que eu começo a abrirme, se quisermos, a outras formas de conhecimento e pensamento não ocidentais que vão dar origem a toda minha discussão sobre, por exemplo, o multiculturalismo hoje. Neste meu último livro, editado pela Routledge, por exemplo, trato da cultura hindu e da cultura islâmica. E estas são, digamos assim, em termos intelectuais, as influências. Depois, nessa altura, também Foucault passa a ser uma referência importante.

\section{P. O senhor diria que a partir do contato com} esse autores, houve uma ruptura em seu próprio pensamento?

R. Não, não é uma ruptura, não há ruptura absolutamente nenhuma. A idéia de ruptura remete a essa coisa, enfim, estúpida, que o Althusser impôs um pouco para todo o mundo, com essas diferenças entre o jovem Marx e o Marx maduro. Isso é uma asneira total que não tem sentido nenhum! Naturalmente, no pensamento de todas as pessoas que trabalham durante uma vida suficientemente longa, há sempre presenças e evoluções. Se as pessoas forem inteligentes e continuarem a trabalhar vão inovando, ou seja, elas não se repetem. Ou, pelo menos, não se limitam a repetir-se, o que, infelizmente, é o que eu vejo muito hoje na vida acadêmica, as pessoas a repetirem ad nauseum sempre as mesmas idéias. É preciso trabalhar para inovar! Mas o problema é que quanto mais inovação ocorre, mais as pessoas pensam que está havendo uma ruptura! Não há propriamente uma ruptura; o que há é uma grande transformação. Agora, quando todos nós passamos por mudanças - e minha geração passou por várias transformações políticas importantes - naturalmente que isso significa alguma coisa. Por exemplo, o fato de eu ter trabalhado nas favelas do Rio de Janeiro é uma opção científica mas é uma opção também política. Queria ver a realidade do outro lado, contra os preconceitos de uma Universidade elitista. Outro marco político ocorre em 1974: a "Revolução Democrática dos Cravos" em Portugal, o "25 de Abril", foi uma revolução que eu vivi absolutamente e intensamente, até porque eu era professor e tinha acabado de chegar dos Estados Unidos para uma nova faculdade que tinha sido criada, exatamente com os liberais, no sentido de abrir um pouco o regime. Era uma faculdade de economia, inaugurada em 1973, e eu fui o primeiro professor doutorado dessa universidade. Rebenta a revolução e eu dou comigo à frente da Faculdade de Economia, eleito Diretor pelos estudantes. E ai fiquei durante vários anos. Depois, fui presidente do Conselho Científico e, mais tarde, coordenador daSessão de Sociologia e diretor do Centro de Estudos Locais. Esse período, digamos, revolucionário em Portugal, foi um período de grande radicalização democrática, que teve o condão de nos por em contato com diferentes formas de democratização, com diferentes teorias democráticas que extravasavam do modelo liberal. Portanto, no fundo, foram muitas as experiências que me levaram - até onde era possível - a um conhecimento do pensamento moderno e à tentativa de superá-lo. E, obviamente, em toda essa formação, sempre me mantive extremamente sensivel à injustiça social. Eu acho que, talvez, isso possa caracterizar um pouco melhor o fato de eu querer manter a minha capacidade de indig- 
nação e de espanto em relação à injustiça social. Não é por acaso que meu penúltimo livro se chama Pela Mão de Alice - o que remete ao espanto de "Alice no País das Maravilhas". Ou seja, é necessário que a gente continue com a capacidade de se espantar, porque a miséria, a fome e a injustiça estão tão espalhadas que a gente habitua-se a vêlas com alguma indiferença. Foi essa capacidade de indignação, combinada com o conhecimento profundo do pensamento moderno - cuja falência eu pude detectar na minha experiência - que levam à conformação de um "pensamento pós-moderno de oposição". Uma tentativa de arregimentar uma teoria crítica que nos permita resolver alguns problemas modernos mas não em termos modernos, por pensar que os problemas modernos não são suscetíveis de uma solução moderna. É impossivel pensar hoje em desenvolvimento, em qualquer lugar do planeta, nos moldes desse modelo que a gente tem. Hoje, um desastre ecológico num país se alastra e se reflete no resto do planeta, imediatamente, de um dia para o outro. Temos de encontrar formas que nos permitam ver alternativas de transformação social e vê-las com suficiente autonomia em relação aos limites teóricos e analíticos que o mundo moderno construiu; daí o "pós-moderno de oposição".

\section{P. O senhor acredita na existência de um} trabalho sociológico que não se fundamente na grande narrativa? $O$ seu trabalho pretende romper com as grandes narrativas das ciências sociais?

R. É uma boa pergunta, na medida em que, talvez, essa idéia das grandes narrativas e das meta- narrativas, que, depois de Lyotard, de alguma maneira, se transformou no cerne comum da discussão epistemológica, seja um falso debate. Isto é, se nós quiséssemos pôr algum rigor nessa discussão do que é uma pequena narrativa ou uma grande narrativa, até onde uma pequena narrativa é pequena, quando é que uma pequena narrativa "incha um bocado" e se torna uma grande narrativa... todos nós usamos uma metáfora quantitativa para problemas epistemológicos que são qualitativamente distintos. Não sei se essa é a maneira correta de formular as questões. O que é correto e o que é genuíno dentro desse debate, é que hoje nós estamos atentos ao fato de que a teoria que nós produzimos não tem um caráter universal, no sentido de que ela não pode captar totalmente a realidade que a gente quer captar. Ou seja, há, de alguma maneira, algo sempre inteorizável na própria realidade, a qual, por sua vez, não é uma realidade fática, positivisticamente captada, porque ela é, também, socialmente construída, o que significa que há diferentes formas de conhecimento e que os nossos conhecimentos científicos captam apenas uma parte dessa realidade, sendo que uma outra parte certamente é captada por outros conhecimentos alternativos. Há uma incompletude nas nossas teorias e isso significa que devemos exercer um certo comedimento em relação às nossas pretensões teóricas. Quando nós atravessamos culturas, ou vamos de uma cultura a outra, isso torna-se ainda mais claro. Ou seja, não só a nossa linguagem como a posição a partir da qual a gente fala, mostram que a nossa maneira de ver o mundo e a realidade é muito mais limitada do que suas pretensões universalistas, na 
medida em que ela muitas vezes cobre apenas uma pequena parte da humanidade. Na verdade, grande parte da teorização sociológica que a gente faz, fá-la normalmente tendo em mente sociedades desenvolvidas da Europa e dos Estados Unidos. Portanto, eu penso que essa pergunta levanta bem a questão de estarmos atentos a uma fragmentação da experiência humana, a uma grande tolerância discursiva para diferentes formas de ver a realidade. Mas, no meu entender, de qualquer maneira, seria uma armadilha se nós, com isso, pretendêssemos dizer que não há uma grande narrativa do capital neste momento. E é essa outra coisa que distingue o "pós-moderno de oposição" do pósmoderno celebratório à la Lyotard, à la Maffesoli, à la Baudrillard etc - porque, evidentemente, há de fato um capitalismo que se globaliza cada vez mais e esse modelo, naturalmente, pode ser uma grande narrativa a partir da qual a gente talvez hoje pense que, para combatê-la, não temos à nossa disposição uma narrativa do mesmo porte. Temos que encontrar diferentes energias em diferentes grupos sociais, com diferentes sujeitos e atores sociais, recorrendo a diferentes formas de conhecimento. Estamos realmente numa posição em que essa grande narrativa da globalização do capital tem que ser confrontada com diferentes conhecimentos promovidos por diferentes grupos sociais que não têm questão de estar sujeitos à mesma lógica de um grande sujeito histórico e de um pensamento monolitico que the cobram as suas ações.

P. O senhor admite que todo conhecimento é local e parcial. A ciência, apesar de hegemônica, é uma entre as tantas formas epistemológicas que o senhor distingue. É também o mais bem sucedido globalismo localizado. Vê-se, portanto, que a ciência também é parcial e local. Como então fazer dela o terreno privilegiado para a construção de um novo senso comum que se pretenda uma utopia para a sociedade mais ampla? É esse o papel das ciências sociais nessa transição? Em que medida isso não implica dar continuidade aos tantos epistemicídios que a modernidade engendrou?

R. É evidente que há esse risco. Eu tenho sempre dito que todo o trabalho teórico e o próprio trabalho político que nós empreendemos num período de transição paradigmática como este que estamos atravessando é um trabalho e uma prática de alto risco. Ou seja, tem grandes possibilidades de ser subvertido no processo de ser aplicado, isto é, grandes lutas democráticas podem, eventualmente, transformar-se em lutas reacionárias. Lutas pelos direitos humanos podem converter-se no oposto. Lutas ecológicas podem se transformar na justificação de alguns despotismos. Então, temos que dar atenção também ao tipo de conhecimento alternativo que estamos a tentar desenvolver. Não descarto essa hipótese e é bom que não se descarte, porque isso é realmente o sentido da vigilância epistemológica. Eu penso que a questão da vigilância epistemológica que, aliás, Bachelard tanto salientou, é importante, só que ele não foi suficientemente vigilante, porque ele apenas nos incitou a termos vigilância contra o senso comum e não nos incitou a termos vigilância epistemológica contra a própria ciência que vai contra o senso comum. E daí, que no livro 
Introdução a uma Ciência Pós-moderna eu diga que nós necessitamos de uma dupla ruptura epistemológica. Nós temos que romper com o senso comum mistificatório que é, no fundo, a evidência do conhecimento popular em sociedades injustas como as nossas. Essa ruptura se faz com a ciência e não posso descartar a ciência moderna para isso; só que não posso ficar nela, é preciso depois fazer uma segunda ruptura epistemológica, no sentido de romper e criar um outro senso comum. Um senso comum mais emancipador, mais libertador. E é aí que entra toda a questão do conhecimentoemancipação e do conhecimento-regulação. Agora, é evidente que nada se pode fazer, senão a partir daquilo que existe. Portanto, a ciência moderna pode ser utilizada de diferentes formas. Eu penso o que a epistemologia feminista é, talvez, aquela que na década de oitenta melhor nos mostrou que a possibilidade de utilizar os instrumentos da ciência moderna de uma maneira diferente através de um novo "conhecimento situado" em que o sujeito epistemológico e o(s) sujeito(s) empírico(s), sabe(m) que as suas posições são contextuais. Elas nos mostram os limites desses conhecimento ao mesmo tempo em que nos apontam para outros processos e outras práticas de conhecimento. São processos paulatinos e revolucionários. São revolucionários no sentido austromarxista; isto é, são processos estruturais civilizacionais, que levam de cem a cento e cinqüenta anos para se realizar e que, portanto, exigem de toda a sociedade muita paciência ... "uma paciência infinita", como eu digo em Alice. É esse tipo de transformação que está aí. A ciência moderna não pode ser aceita em seus termos exclusivos, não pode ser descartada também como algo que seja eminentemente reacionário. Temos que ter, durante muito tempo, uma hermenêutica de suspeição em relação a ela e, portanto, utilizá-la, mas utilizá-la com os seus limites e para aprofundar esses mesmos limites. E é quando a gente aprofunda os limites da epistemologia moderna que a gente vai abrindo espaços para outras formas de conhecimento. Abre-se um período de grande tolerância discursiva mas, ao mesmo tempo, combinado com uma grande atenção às intolerâncias que muitas vezes não são discursivas e que são, baseadas exatamente na exclusão dos discursos, no silêncio e no silenciamento. É esse o meu debate, na verdade.

P. Quanto mais extenso o conceito, menos compreensivo. $O$ senhor não acha que esse é um problema que ocorre com o conceito de globalização, ainda que em sua "forma plural"? R. Eu acho que o meu conceito de globalização não é global. Não é tão genérico assim, primeiro porque nada é global no meu conceito de globalização, que pode ser compreendido como um processo de difusão e de amplificação, cujas relações sociais devem ser identificadas e conhecidas. O que nós temos, portanto, é uma nova escala de fenômenos e uma nova transformação de escalas. Temos fenômenos locais que se globalizam. Quando a gente fala dos hambúrgueres, dos modelos de estrelato cinematográfico, fala de processos locais que, de repente, começam a mudar de uma pequena escala para uma grande escala. Temos que analisar essa diferença e essa transformação de escalas. Portanto, o fato de eu 
articular certos processos de globalização como processos de localização - e o fato de eu distinguir diferentes formas de globalização - de alguma maneira me defende um pouco contra conceitos pouco determinados.

P. Esse conceito de globalização contempla uma estética? Algumas vezes, temos a impressão de que a globalização se confunde com a universalização e se distingue da estética porque a estética trabalha mais com o particular e o universal, e não com o local e o global. Gostaria de saber se há uma preocupação em relação a isso, a não estar contemplando o estético, ou se não é mais possível pensar num discurso sobre estética hoje, diante do fenômeno da globalização. R. Eu não estou a fazer nem uma teoria e nem uma filosofia da estética, não é isso que me interessa. Mas, certamente, uma sociologia da estética cabe perfeitamente dentro da minha preocupação com a globalização/localização, ou seja, como que hoje, através exatamente do mass media, é possível universalizar ou globalizar como eu prefiro dizer - formas estéticas que são absolutamente particulares. Por que razão é que na publicidade mediática do Brasil as mulheres brasileiras são quase sempre louras? Isso significa que há formas que se difundem e que deixam na sombra todas as demais. Portanto, a estética, enquanto sistema filosófico está num outro campo. É o campo de uma reflexão que eu penso que tem que ser feita a partir de certos preceitos. Avanço alguns deles no meu capítulos sobre Epistemologia Não Fundacional ${ }^{3}$, do meu último livro. Em termos sociológicos, o que vai acontecer é nós vermos que diferentes sociedades são capazes de ter conceitos estéticos diferentes de outras e algumas resistem melhor a fenômenos de globalização, outras intensificam os seus conceitos de belo e seu vernáculo de belo para resistirem melhor. Não necessariamente para serem competentes no sistema global, mas para serem melhores. Se nós ligarmos a estética ao corpo, hoje a sociologia finalmente começa a tratar diretamente a teoria e a análise do corpo, em diferentes sociedades e sob o impacto de fenômenos que parecem simétricos - veremos que no Brasil, por exemplo, se considera que há uma muito maior manipulação do corpo do que em outros paises que possuem o mesmo nível de desenvolvimento. A cirurgia estética, por exemplo, $o$ alto índice de cesarianas que aqui sãc realizadas... Portanto, há culturas do corpo que, a exemplo da cirurgia plástica, são extremamente populares e que, eventualmente, podem se: compreendidas como o "correspondente corporal da cirurgia psicanalítica, que também os meus amigos da classe média paulistana normalment: preferem como forma de dar uma boa estética : sua alma.

P. Sobre o corpo, há teorias que versam que. no Brasil, esse corpo sem muitas fronteiras. muito facilmente envasado pelo poder atravanca 0 processo democrático. $O$ senho: concordaria com isso? Até que ponto isso nã significa determinar um desenvolvimento a moldes do desenvolvimento das civilizaçōe centrais? Em contrapartida, essa cultura d

3 Souza Santos, B., 1995, opus cit. 
corpo poderia significar um caminho alternativo: o corpo, no Brasil, está tradicionalmente ligado a um sensualismo, ele é valorizado por isso. Então, o corpo, no Brasil, transitaria entre esses dois pólos: a violência e a valorização. Até que ponto o corpo pode ser matéria daquela primeira leitura, liberal e civilizatória?

R. Bom, eu penso que exatamente na forma como formulou a questão, o comentário me parece correto, ou seja, essa valorização do corpo é o outro lado do suplício do corpo. O sensualismo é o outro lado da escravatura, muitas vezes, e não estão tão distintos um do outro. São sociedades que permitiram às elites valorizar muito o corpo, na medida em que também foi profundamente desvalorizado em todas as classes que não pertenceram à elite. $\mathbf{O}$ suplício do corpo no Brasil, a violência física, as mortes que nós assistimos aqui em São Paulo, isso são, obviamente, formas de desvalorização dramática do corpo e da vida, que são o outro lado do cuidado do corpo por parte das classes sociais que têm o privilégio do direito ao corpo.

\section{P. O senhor defende que a globalização está mais} longe da homogeneidade e mais próxima da singularidade, pois parte de uma localização. Na cultura de massas ainda é possível essa distinção? Não são todas banalizadas pelo consumo?

R. Eu não defendo, necessariamente, que a globalização esteja mais longe da homogeneidade do que a singularidade. $O$ que eu penso é que ela joga com ambas e joga em certos domínios com a homogeneidade e em outros com a singularidade e tanto uma como outra são falsas, na medida em que se apresentam como totais. A globalização joga exatamente com essas duas características e, portanto, acho que não se pode compreender a globalização sem os processos de localização. É que esses processos, normalmente, são processos de poder, daí, por exemplo, que nos meus trabalhos e nos meus modelos analíticos e na teorização no nível da análise dos modos de produção de poder - o espaço mundial seja tão importante. Por que razão é que eu ponho o espaço mundial como um espaço importante? Exatamente por pensar que hoje, nas sociedades nacionais, é fundamental analisar esses impactos da globalização, precisamente porque há certos paises que conseguem globalizar os seus localismos, enquanto outros se limitam a sofrer esses impactos e, portanto, têm menos capacidade de colocar no mercado global a sua identidade e as suas especificidades. E com isso, na minha construção teórica, este espaço mundial é concebido como um dos espaços estruturais das sociedades nacionais. Quer dizer, o espaço mundial é um espaço interno, é parte integrante da sociedade nacional. É o conjunto dos impactos da globalização e da posição de um país no sistema mundial dentro desse país com a sua cultura, com seu sistema escolar, na sua alimentação, na sua maneira de vestir etc. $O$ espaço mundial é um espaço interno, não é uma influência externa. Claro que a cultura de massas desenvolveu-se muito a partir do conceito de massas um conceito que se pretendeu que viria a suplantar o conceito das classes. Portanto, de alguma maneira nós teríamos hoje sociedades que nivelaram por baixo os cidadãos face ao Estado; pode 
haver classes, mas o que é determinante é essa noção hierárquica entre o Estado e as massas, que são constituídas na sociedade. A cultura de massas acabou por ser exatamente o nome que nós atribuímos a essa relativa indiferenciação social que se constitui nas relações de hierarquia com o Estado. No entanto, se analisarmos hoje o que é a cultura de massas, ela está muito longe desse modelo. Ou seja, é uma cultura de diferenciação, é uma cultura de clientelização, uma cultura de personalização e, não, necessariamente, uma cultura da indiferenciação e da homogeneidade. Quando muito, são homogêneos os padrões cuja homogeneidade nos escapa. $\mathbf{O}$ que a gente vê são as diferenças, isto é, não pode haver uma infinita variedade nos corpos ou nos estilos de roupa, porque as máquinas não se acomodam a toda essa grande variedade. Há padrões, portanto, mas eles são suficientemente maleáveis para nos dar a ilusão de que tudo é possível. Ee é isso, no fundo, que é a lógica da cultura de massas. Por um lado nos dá a ilusão de que tudo é possível e, por outro, esconde o que é impossível. Ou o que é impossível não existe. É por isso que eu sempre digo: "temos que fazer uma sociologia do que não existe".

P. Em escritos mais recentes, o senhor destina um lugar bem menos importante para a media e para a cultura de massas, o que é compreensível num pensamento que busca formas alternativas de construção de utopias. Entretanto, em outras ocasiōes, o senhor menciona o fato dos artefatos da cultura pós-moderna entrarem diariamente em nossas casas. Como construir utopias numa sociedade que se torna, ela mesma, o lugar da não reflexão?
R. Provavelmente, através de medias utópicas. Eu penso que a questão dos media ou dos mass media está relativamente sub-teorizada no meu trabalho. É uma das incompletudes do meu trabalho que, em parte, deve ser problematizada. Digo em parte, porque não tenho pretensões de estar a produzir respostas para todos os problemas teóricos da atualidade. Muitos problemas me escapam, naturalmente. Mas estou muito atento àquilo que não me escapa e esse fato me exige muita cautela. Portanto, o que hoje me chama muito a atenção e é por onde eu pretendo trabalhar um pouco - é toda essa questão das medias interativas, as várias medias locais, as novas formas de luz e de espaço eletrônico que possam, de alguma maneira, utilizar aquilo que eu chamo mediatrizes, que são as formas através das quais nós podemos construir o espaço mediático em termos sociais, ou seja, em termos de relações sociais. Eu penso que nesse momento eu não gostaria de avançar muito mais, porque é um trabalho ainda em construção, sobretudo porque essa questão do espaço, o ciberespaço, espaço eletrônico, espaço virtual, de alguma maneira, obriga a uma teorização de outro tipo e eu ainda não me convenci se estou a teorizá-la com instrumentos analíticos que foram desenvolvidos para outro tipo de espaço ou se pelo contrário há a necessidade de construção de um outro tipo de teorização.

P. Aqui, mais do que no primeiro mundo, a media fala pelos sujeitos. Eles são silenciados ou convidados a participar. Há nesse silêncio a elaboração de uma utopia, sendo essa uma espécie de resistência surda, ou a elaboração de utopias fica restrita ao quartel dos intelectuais progressistas? 
R. Eu acho que essa questão tem toda a razão de ser, ou seja, o silêncio, como fenômeno sociológico, está sujeito às condições sociais que condicionam, de uma ou de outra forma, outras formas de silêncio. Quer dizer, a fome é uma forma de silêncio, silêncio do corpo, a subnutrição, a miséria são déficits e esses déficits devem ser analisados como tal. Os silêncios são socialmente distribuídos e só aqueles que podem falar é que podem falar do silêncio. E daí o sentido da sua questão. É possível falar em silêncio do silêncio? Essa questão é importante. Agora, por que a questão silêncio não é a mesma que a questão da fome, necessariamente? É porque há fomes e fomes. Há fomes voluntárias, por exemplo, todas as religiões têm um período de jejum. A cristandade tem seus períodos de jejum, seja o catolicismo, seja a cultura islâmica, seja a religião judaica. $\mathrm{O}$ ascetismo medieval, por exemplo, era um ascetismo de fome voluntária. Mas a esmagadora maioria das fomes é uma fome imposta pelas condições sociais. Agora, eu penso que a questão do silêncio é um pouco mais complicada. Ou seja, há muito silêncio imposto, mas também há muito silêncio desejado, há muito silêncio onde a imposição não é direta. Existem pessoas que optam, por exemplo, por não participar das eleições, não se manifestar, numa conversa ficarem caladas. Não porque alguém as estejam impedindo de falar, mas porque pensam que não têm nada a dizer, o que é uma forma de controle social. Ou porque não encontram uma linguagem adequada que transmita o que elas queiram dizer ou porque, pura e simplesmente, não querem participar. Portanto, o silêncio é mais polissêmico na sua constituição disciplinar do que a fome.
P. E quanto à participação? $O$ exercício ou a recusa à participação não seriam também produzidos e controlados socialmente? Ela também não seria mais polissêmica em sua constituição?

R. Sim, com certeza, a participação seria também mais polissêmica em sua constituição do que a questão da fome. Agora, é evidente que um dos grandes problemas da nossa cultura é de que nós não temos uma cultura de silêncios. Somos uma cultura pouco dada à meditação. Somos uma cultura muito mais dada às palavras e aos ruídos.

P. O senhor afirma em Pela Mão de Alice que um dos principais epistemicídios levados à prática pela modernidade ocidental deu-se simbolicamente a 14 de janeiro de 1492, com a queda de Granada e a posterior dizimação de toda uma tradição de pensamento, cujas origens remontam às grandes civilizações do Vale do Nilo. Parece-me que o senhor mesmo chegou a dizer em suas obras que trata-se de buscar uma reparação dessa tradição massacrada. Poderíamos também conectá-la a uma outra tradição massacrada pela modernidade ocidental, a sofística. A tradição platônica acabou por tornar-se imperiosa sobre o seu mundo. $\mathrm{Na}$ maioria das línguas ocidentais palavras como sofisma são sinônimo de falsidade, são signos de conteúdo depreciativo, fenômeno parecido com a palavra retórica. De certa forma, no caso específico dos sofistas, parece-me que Hanna Arendt e Nietzsche, dentre outros, também reivindicam uma tradição sofisticada para a cultura ocidental. Então, se assim é possível 
pensar, no campo do saber ocorre uma busca de uma identidade baseada nas ruínas de uma tradição massacrada. Esta, por sua vez, baseada no poder do convencimento, na oralidade, no poder da palavra, na retórica, na ausência de essências. Gostaria que o senhor comentasse a relação dessa busca de uma identidade alternativa, no campo do saber, com aquilo que o senhor denomina cultura de fronteira, uma cultura que não tem conteúdo, não tem essência, só tem forma, e cujas fronteiras estão aí para serem ultrapassadas, atravessadas.

R. É uma excelente questão, que leva para um bom ensaio. Infelizmente, respondendo brevemente, certamente corro o risco de o fazer simplisticamente. É evidente que nós podemos pensar que a tradição da sofística - ocidental, se quisermos, ela própria com outras tradições menos ocidentais que por vezes tenham sido esquecidas - é talvez o grande ancestro, o grande percursor da hermenêutica de suspeição. É talvez também, o grande percursor da desconstrução, porque é um pensamento desconstrutivista. Nesse sentido, tem também um lugar em todas as formas epistemológicas que se afirmam pelo não fundacionalismo, pela desconfiança em relação à representação do real, pela desconfiança em relação às verdades $\mathrm{e}$ pelo pensar que as verdades são, acima de tudo, discursos de verdade. Agora, a diferença que há com a retórica é que a retórica, como teoria da argumentação - é assim que eu a entendo - é fundamentalmente uma forma de conhecimento que não é apolítica, no sentido aristotélico. É uma forma que só se pode afirmar pelo grau de convencimento ou de persuasão que cria através de uma argumentação, que, para ter um lugar, tem que ter um auditório e tem que ter participação desse auditório. Não é por acaso que a retórica, mesmo na antiguidade clássica, só prosperou nos períodos democráticos. Exatamente porque é um pensamento incompleto, é um pensamento em que o argumento puxa argumento, em que uma noção puxa uma contra-noção. Naturalmente que a tradição desse pensamento é, para mim, fundamental. Acho que é a forma de pensamento mais consentânea ou isomórfica com uma prática socialdemocrática. Agora, de novo e sempre, desde que a gente tome bem atenção sobre quem é que participa do discurso, quem é que é excluído do discurso, porque é que certos argumentos são mais fortes em certos momentos e não noutros, porque que são mais fortes em certos auditórios e menos fortes noutros. Ou seja, eu não compreendo a retórica sem uma sociologia da retórica, sem uma reflexão sobre a própria força dos argumentos. Portanto, eu penso que essas duas tradições são muito importantes para a constituição do meu pensamento, ainda voltando à questão sobre os intelectuais. Se tem a ver com a cultura de fronteira, eu formulei o conceito de cultura de fronteira - e é muito interessante até na gênese dos novos conceitos, porque a gente normalmente formula-os a pensar em certa realidade e depois, de repente, dá-se conta que esses conceitos tem uma virtualidade analítica muito mais ampla do que aquela que foi prevista por nós originalmente - quando estava fundamentalmente a tentar dar conta da cultura portuguesa $\mathrm{e}$, indiretamente, da cultura brasileira, por serem culturas que viveram em grandes trânsitos, sendo que a cultura por- 
tuguesa em trânsitos internacionais. De um país pequeno que, de repente, se globaliza nos séculos XV e XVI e que, a partir daí vai ter toda uma diáspora espalhada pelo mundo com uma cultura que eu considero bastante cosmopolita, isto é, com uma grande capacidade de identificação com as culturas locais, de perda das identidades de origem, perda da língua, o que tem sido visto até negativamente e que eu considero ser uma grande positividade da cultura portuguesa. Ou seja, muito pouco nacionalista, digamos assim, na sua própria constituição. $\mathbf{O}$ importante daí é que essa cultura fosse mais uma cultura que tinha uma forma, que era a forma de fronteira, uma forma de porta de vaivém, que está sempre nas correntes de ar, que está sempre aberta a diferentes experiências e que vai construindo suas identidades a partir das diferentes experiências com culturas as quais contacta. Depois dessa formulação, que aparece em Pela Mão de Alice ${ }^{4}$, eu comecei a ver as virtualidades desse conceito para a tentativa da criação das subjetividades utópicas, aí eu fiz uma leitura bastante diferente da cultura de fronteira e comecei a teorizar essa questão no último capítulo de Toward a New Common Sense ... 5 , no qual eu trato das três grandes metáforas do pensamento de utopias, onde uma das metáforas é exatamente a fronteira. Portanto, o conceito de fronteira aparece aí e, esse sim, é um conceito muito importante para entender como se criam e se estabelecem certas comunidades utópicas que são as comunidades-ameba, as comunidades que se abrem ao outro mais facilmente.

4 Souza Santos, B., 1995a, "Modernidade, Identidade e Cultura de Fronteira": 135-160, opus cit.
P. O fato é bastante recente - foi de ontem ou de anteontem para cá, e, portanto, essa questão não é ainda conseqüência de uma reflexão mais apurada - mas está ligada à absolvição de $O$. J. Simpson. $O$ ato do tribunal, o empenho das duas partes, da diç̧ão e da contra-dicção, é a busca da verdade, ao menos teoricamente. Temos esse fato que uma mulher foi morta com o namorado. Tem-se algumas provas mais evidentes, outras nem tanto. Há uma absolvição. Esperava-se, inclusive, o contrário. $E$ parece que o que contou menos talvez tenha sido as argumentações, mas o fato de que, se ele fosse condenado, haveria uma catástrofe, uma rebelião do tipo da que aconteceu quando um negro foi espancado em Los Angeles. Então, fugiu totalmente de uma certa tradição do papel do júri, da investigação, que é um dos modelos da retórica. Há ainda um agravante ético: o medo de que, caso ele fosse condenado, tivesse havido discriminação racial. É esse o grande argumento. Como é que fica, então, essa questão? É muito cedo ainda para se refletir sobre isso?

R. Não. Não é assim tão cedo. Eu acho que há duas coisas relevantes. Em primeiro lugar, esse julgamento não põe de modo nenhum em causa a constituição de conhecimentos jurídicos como conhecimento retórico, o que nos obriga a refletir sobre o tipo de retórica e o tipo de argumentação que domina em determinado processo. E aqui é uma coisa curiosa que eu tenho chamado a atenção para o fato de que a ciência é, em si mesma, uma retórica. E o argumento, a retórica do argumento

5 Souza Santos, B., 1995, Part Four: "Utopia, Emancipations and Subjectivities", Chapter 8 - "Don't Shoot the Utopists", opus cit. 
científico, é ele próprio uma retórica a qual, naturalmente, se articula, num julgamento, com outros tipos de retórica. $\mathrm{O}$ que aconteceu, no caso de O. J. Simpson, é que se sobrepuseram duas retóricas, dois tipos de argumentação. Em primeiro lugar, a retórica científica. Nunca, em nenhum processo, num julgamento recente nos Estados Unidos, houve tanta análise biológica e química e tanta retenção de detritos, restos, fragmentos e vestígios para tentar, com as tecnologias mais avançadas, alcançar uma "verdade absoluta". Em segundo lugar, uma sub-retórica - mas que pouco a pouco se foi transformando numa retórica dominante - que é uma retórica racista e interracista: certas declarações que foram consideradas racistas e que levaram a defesa a jogar forte na cartada do racismo. Estamos na Califórnia, estamos numa cidade e numa região atravessada e avassalada por certos motins raciais e, naturalmente, que a defesa foi exímia em usar a argumentação racista ou étnica. Ou seja, o que nós estamos aqui é a julgar uma etnia, é a raça negra, porque, de outra maneira não haveria certo tipo de argumentação ou certo tipo de prova, as provas não teriam sido forjadas como foram etc. $\mathrm{O}$ que significa que a retórica étnica prevaleceu sobre a chamada retórica científica.

\section{P. Essa questão gira em torno de uma reflexão} sobre a cidade atual. A grande utopia modernista era a cidade como organismo perfeitamente funcional, planejado racionalmente, onde cada função teria seu local especificado. Como utopia vencedora, ela agiu sobre o seu presente, modificando-0, e Brasília é a quase-síntese desse êxito. Mas, como qualquer utopia, ela deiron espaços sem tocar. Vestigios de outros e de vários tempos, a utopia, ao defrontar-se com a história, transformou-se em heterocronia e em heterotopia. Dentro desse contexto, poderíamos considerar que um dos grandes insights de $\mathbf{W}$. Benjamin foi revelar essa dimensão outra da cidade, essa cidade arruinada e fantasmagórica por onde caminhava Baudelaire. A cidade retomada por Haussman também produzia as ruínas que se levantavam nos versos do poeta. Hoje a cidade deixa de ser o principal suporte espacial da acumulação capitalista. Poderíamos, de alguma maneira, falar em cidade pósindustrial. Se o capital trafegava pelas artérias urbanas, hoje ele ganhou asas, fios e satélites. Então, saímos a caminhar por essa cidade fantasma - se assim nos permitem o discurso da periculosidade das ruas ou da Internet - e pisamos sobre ruínas. $O$ que nos dizem essas ruínas, ou melhor, sobre o que elas nos indagam?

R. Bem, é uma pergunta muito bem formulada. Não é verdade, no meu entender, que a cidade deixe de estar sendo o suporte espacial do desenvolvimento e da acumulação capitalista. Eu penso que nós não estamos diante do "fim das cidades". É evidente que a utopia modernista da construção de cidades - que aliás, caminhou passo a passo com a arquitetura modernista - além de criar uma nova racionalidade na cidade, teve uma origem extremamente emancipadora. Não era tanto uma lógica de poder, mas uma lógica de anarquia. Curiosamente, os grandes planejadores urbanos do século XIX são anarquistas e não estão tão 
preocupados com a questão do poder. Na verdade, as cidades modernistas - e eu penso que Brasília é uma caricatura de Le Corbusier - já são uma caricatura onde já impera, fundamentalmente, uma lógica de poder. Foi esse projeto modernista que se pôs ao serviço do poder capitalista na cidade e na arquitetura modernista! Portanto, o que está hoje em crise não é, exatamente, a questão da acumulação capitalista. Ao contrário, o que me parece, é que essa forma de acumulação pode conviver hoje - e realmente convive - com diferentes formas de cidade e com diferentes formas de arquitetura.

\section{P. Num espaço diferente da própria cidade, quer} dizer, num espaço cibernético, num não-espaço. R. É um espaço cibernético que, no entanto, ocorre entre cidades. É uma rede de cidades, uma rede extremamente seletiva. $\mathbf{O}$ que fica fora delas, a exclusão? O que fica fora das cidades globais? Se são ruínas - eu falo de ruínas emergentes exatamente para que possamos avaliar exatamente $o$ que ficou de fora da utopia modernista das cidades ou da arquitetura modernista - há algum sinal de futuro. Como sempre, devemos buscar a arqueologia da modernidade para pensar essa questão e, se formos, por exemplo, analisar um bocadinho da arquitetura e da própria cidade moderna que nós podemos encontrar no fím do século, na Austria - especialmente em Viena, onde praticamente começa tudo na epistemologia moderna, com Wittgenstein e Adolf Loos - além de estarmos diante de uma nova racionalidade na cidade, podemos encontrar muitas formas utópicas de se definir o projeto moderno. Formas de vida utópicas que não se traduzem na vida burocrática de Brasília e, sim, na constituição de sociabilidades utópicas que se realizam fora dos limites da cidade medieval e da cidade pré-moderna. Então, de alguma maneira, esses limites, esse elemento utópico, desapareceu um pouco, quando a cidade modernista se transformou na cidade burocrática por excelência e quando a arquitetura modernista da Bauhaus vai dar origem ao chamado estilo internacional, que é um estilo que nós encontramos também aqui em São Paulo. Tanto é um estilo, que realmente é a face arquitetônica das grandes burocracias públicas e privadas! Quando isso se consolida é a utopia que desaparece! Para mim, eu vi a utopia em Brasília nos percursos e nos atalhos que as pessoas fazem no meio daqueles balões e viadutos todos, para caminhar entre aquelas quadras. Elas estabelecem percursos e atalhos quando caminham a pé, que não foram previstos e nem projetados por Oscar Niemeyer.

P. Se a gente anda por São Paulo - não aqui, porque essa parte é "bem falada" em termos urbanísticos - se a gente for falar na dicotomia falado-silêncio no urbanismo e na arquitetura - essa região aqui é privilegiada em termos de capital - mas se a gente descer para o centro da cidade, alí onde ficava o núcleo original da cidade, eu acho que as ruínas da cidade estão alí e eu acho que é alí que a gente deve ver essas brechas históricas, e elas foram muito massacradas. Hoje é muito difícil fazer isso, porque, ao mesmo tempo é o espaço ocupado pelos meninos de rua, pelos camelôs, pela economia informal. Quer dizer, é o espaço ocupado por 
tudo o que foi negligenciado e silenciado pelo modelo de acumulação capitalista.

R. Eu concordo, mas acredito que isso varie de cidade para cidade, porque o que eles ocuparam, muitas vezes, foi apenas o espaço público. Alguns edifícios continuam a serviço ainda dos mesmos interesses, muitas vezes. Em outras cidades, como, por excmplo, Manhatan, muitos dos edifícios deixaram de ter as funções que tinham. Mas hoje, aqui em São Paulo, pode continuar a ter o mesmo poder e o mesmo exercício de poder dentro dos edificios e foi esse espaço público que se informalizou. Que esse espaço público era um espaço de comunicação entre os edifícios e esse, sim, foi ocupado pelo informal e pelo "populacho", digamos assim. Agora, é preciso ver que o conceito de ruínas é um conceito polissêmico, ou seja, há a ruína ruína e a ruina emergente. Quer dizer, há ruínas que são mesmo os restos do passado e há ruínas que são os pedaços de futuro que ficaram nas tradições suprimidas. Aquilo que não se realizou. As ruínas são os restos daquilo que não se fez. 